\title{
Time Of Maximum Resolution Of Diabetic Macular Oedema After Ranibizumab Injection
}

\author{
Mohammed Abd El Wahab Hassan, Hossam ElDin Mohammed \\ Khalil, Abd El Rahman Shaban Ahmed \\ Ophthalmology Department, Faculty of Medicine, Beni-Suef University, Egypt \\ Docto372@gmail.com,01020612137
}

\begin{abstract}
:
Introduction Macular edema occurs in a wide variety of ocular diseases, and an alteration in the blood-retinal barrier (BRB) leads to the accumulation of fluid in the extracellular space and the development of fluid-filled (cystoid) spaces in the outer plexiform layer and the inner nuclear layer of the retina are common findings in cystoid macular edema (CME)..

Aim of the Work : To evaluate the effect of intravitreal injection of ranibizumab on diabetic macular edema (DME).

\section{Patients and Methods}

Type of the study :A longitudinal descriptive randomized study.-

-Site of the study : The patients will be selected random from the outpatient clinic of

National Eye Center of Opthamology in Rod El-Farag.

-Date and period of study : This study was conducted in March 2019.

-Size and type of sampling techniques to choose a representative sample: The study will include 20 eyes of 20 patients selected randomly with the following inclusion and exclusion criteria to receive a single intravitreal injection of ranibizumab.

- 20 eyes with Type II diabetes mellitus with non-proliferative diabetic retinopathy (NPDR) and significant focal or diffuse DME with no foveal serous detachment confirmed by OCT .

Results: Twenty eyes attending the ophthalmic outpatient clinic between March 2019 and December 2019 were selected. They suffered focal or /and diffuse DME, All eyes received primary dose of intravitreal injection of ranibizumab $(0.5 \mathrm{mg})$.
\end{abstract}

Conclusion : The study showed that most patients did not show significant improvement in V/A rather than a significant decrease in central macular thickness after one injection and the improvement was considered less than those patients who had received multiple injections in other studies.

Keywords: ranibizumab, non-proliferative diabetic retinopathy,

Receive Date : 25/2/2021

\section{Accept Date: 5/3/2021}

Publish Date : 1/4/2021

\section{INTRODUCTION}

Macular edema occurs in a wide variety of ocular diseases, and an alteration in the blood-retinal barrier (BRB) leads to the accumulation of fluid in the extracellular space and the development of fluid-filled (cystoid) spaces in the outer plexiform layer and the inner nuclear layer of the retina are common findings in cystoid macular edema (CME). The term 'cystoid' rather than 'cystic' is used because the fluid-filled spaces do not possess the epithelial layer that is present in a true cyst (1). 
ME has been reported in $4.8 \%$ $6.8 \%$ of patients with diabetes (2).

Diabetic macular edema (DME) is the leading cause of vision loss in patients with diabetes in developed countries (3).

One of the pathological events that occur in diabetic retinopathy is the release of vascular endothelial growth factor (VEGF), which is induced mainly by hypoxia (4) .

It has been well established that VEGF plays a vital role in promoting neovascularization and increasing vascular permeability in diabetic eyes. The levels of ocular VEGF are correlated with both the -growth rate and permeability of new vessels (5).

Previous studies have shown that vitreous samples from patients with DME have elevated VEGF levels. Furthermore, introduction of VEGF into normal primate eyes induces the same pathological processes as seen in diabetic retinopathy, namely, microaneurysm formation and increased vascular permeability (6).

It was also found that the growth of new vessels from the retina or optic nerve was thought to occur because of VEGF release into the vitreous cavity in response to ischemia (7).

\section{AIM OF THE WORK}

To evaluate the effect of intravitreal injection of ranibizumab on diabetic macular edema (DME) .

\section{Patients ANd Methods}

\section{Date access :}

Patients:

-Type of study: A longitudinal descriptive randomized study.

Study- site: Patients will be selected randomly from the outpatient clinic of the National Eye Center of Ophthalmology in Rod El-Frag.

-Date and period of study: This study was conducted in March 2019.

-Size and type of sampling techniques to choose a representative sample: The study will include 20 eyes of 20 patients selected randomly with the following inclusion and exclusion criteria to receive a_single intravitreal injection of ranibizumab.

- Twenty eyes with type II diabetes mellitus with non-proliferative diabetic retinopathy (NPDR) and significant focal or diffuse DME with no foveal serous detachment confirmed by OCT.

\section{Ethical considerations}

- Explanation of the aim of the study to the patients in a simple way to be understood by the participants.

- Informed consent written in Arabic will be obtained from the participants with the approval of the ethical committee of the Faculty of Medicine.

- All data will be confidential and will not be used outside the study without patient approval.

- Participants had the right to withdraw from the study at any 
time without giving any reason.

- All participants must be informed about possible side effects of injection, such as endophthalmitis, intraocular pressure elevation, retinal detachment, and ocular hemorrhage .

- No harmful manoeuvres were per ocular hemorrhage formed or used.

- Before injection complete ophthalmological examination was done for every patient.

\section{Eligibility for the study}

- Age eligible for Study: above 40 Years.

- Gender eligible for Study: Both genders were included.

\section{Inclusion Criteria}

- Patients with type II diabetes mellitus with non-proliferative diabetic retinopathy (NPDR) and focal or diffuse DME were confirmed using OCT.

- Glucose levels must be controlled and evaluated using glycosylated hemoglobin $($ HBA $1 \mathrm{c} \leq 7.5)$.

- Patients should have clear ocular media to allow for proper OCT scanning.

\section{Exclusion criteria:}

- Other retinal or macular pathology like ARMD or any occlusive disease affecting retina.
- Optic disc pathology due to chronic glaucoma.

- Patients previously treated with Argon laser or with intravitreal injection.

- Patients with proliferative diabetic retinopathy \pm tractional retinal detachment and vitreoretinal traction.

- Patients with chronic renal failure or history of stroke were excluded from the study.

- Patients with media opacity affecting the cornea, lens, and vitreous that interfere with the evaluation of the macula by biomicroscopy, OCT.

- Patients with pervious history of ocular surgeries.

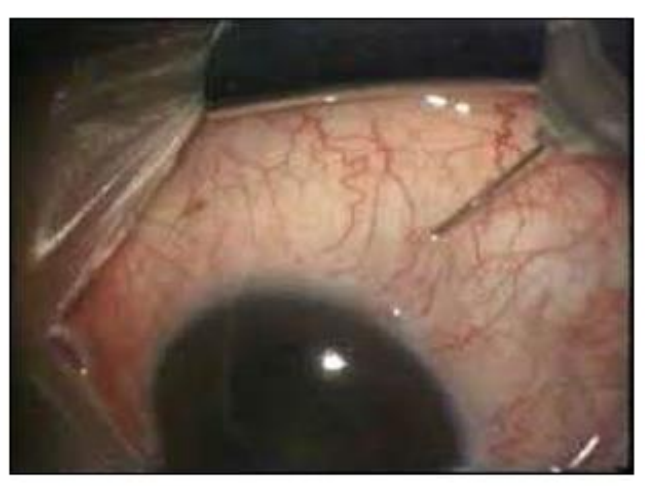

Figure 1: Intravitreal injection in superior temporal quadrant.

\section{Follow up}

- Day 1, day 3, 1 week and 1 month.

- Each patient was followed up to detect changes in visual acuity, CFT and any complications.

\section{Follow up:}

- Best corrected visual acuity. 
- Slit lamp examination and biomicroscopy.

- Applanation tonometry.

- Fundus examination.

- OCT macular thickness one month post-injection was performed in the same way, preoperatively, as data access documents.

\section{Results}

Twenty eyes attending the ophthalmic outpatient clinic between March 2019 and December 2019 were selected. They suffered focal or /and diffuse DME, All eyes received primary dose of intravitreal injection of ranibizumab (0.5 mg).

8 males, 5 females, their ages ranges from40-65 years with mean (49.3 \pm 10.01$). \log$ Mar visual acuity with mean $(0.4 \pm 0.26)$ before injection. CFT using OCT had a mean (323.90 \pm $146.72 \mu \mathrm{m}$ ) before injection.

P-value >0.05: Non significant (NS); P-value <0.05: Significant (S); Pvalue $<0.01$ : highly significant (HS)

*:Chi-square test; $\bullet:$ independent $t$ - test

\section{Description}

\begin{tabular}{|c|c|c|c|}
\hline \multicolumn{2}{|c|}{ Count } & $\%$ \\
\hline \multirow{2}{*}{ Side } & Right & 10 & $50.0 \%$ \\
\hline & Left & 10 & $50.0 \%$ \\
\hline
\end{tabular}

Table (3) showing laterality

\begin{tabular}{|l|l|l|l|l|l|}
\hline & Mean & \multicolumn{2}{|c|}{$\begin{array}{l}\text { Standard } \\
\text { Deviation }\end{array}$} & \multicolumn{2}{|c|}{$\begin{array}{l}\text { Minimu Maximu } \\
\mathbf{m}\end{array}$} \\
\hline Age & 49.30 & 10.01 & 52.50 & 33.00 & 62.00 \\
\hline
\end{tabular}

Table showing age of patient's data

\begin{tabular}{|l|l|l|l|l|l|}
\hline & Mean Std Dev & Median & Minimum & Maximum \\
\hline $\begin{array}{l}\text { Sphere before } \\
\text { injection }\end{array}$ & 81.25 & 26.00 & 87.50 & 20.00 & 135.00 \\
\hline $\begin{array}{l}\text { cylinder } \\
\text { before } \\
\text { injection }\end{array}$ & -1.34 & 0.87 & -1.00 & -3.00 & 0.50 \\
\hline $\begin{array}{l}\text { axis before } \\
\text { injection }\end{array}$ & -0.41 & 3.48 & 0.50 & -7.50 & 3.75 \\
\hline $\begin{array}{l}\text { V/A before } \\
\text { injection }\end{array}$ & 0.40 & 0.26 & 0.40 & 0.05 & 0.80 \\
\hline $\begin{array}{l}\text { macular } \\
\text { thickness } \\
\text { before } \\
\text { injection }\end{array}$ & 332.9 & 146.72 & 294.50 & 180.00 & 700.00 \\
\hline
\end{tabular}

Table showing measures of patients, V/A, macular thickness before injection 


\section{Examples of cases:}

\section{Case 1}

Thickness Map Change Report, All Follow-Ups SPECTRALIS $\otimes$ Tracking Laser Tomography

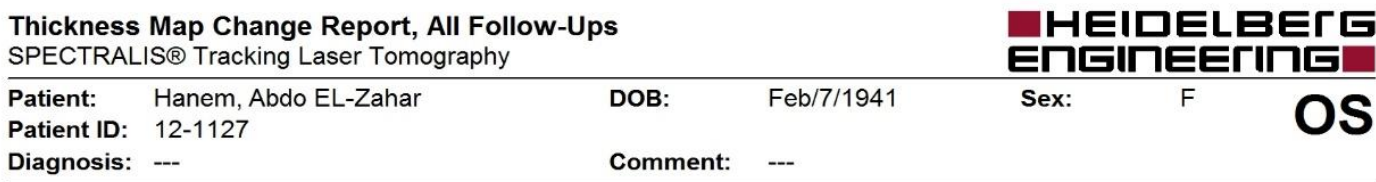

Diagnosis: ---

Comment: - -
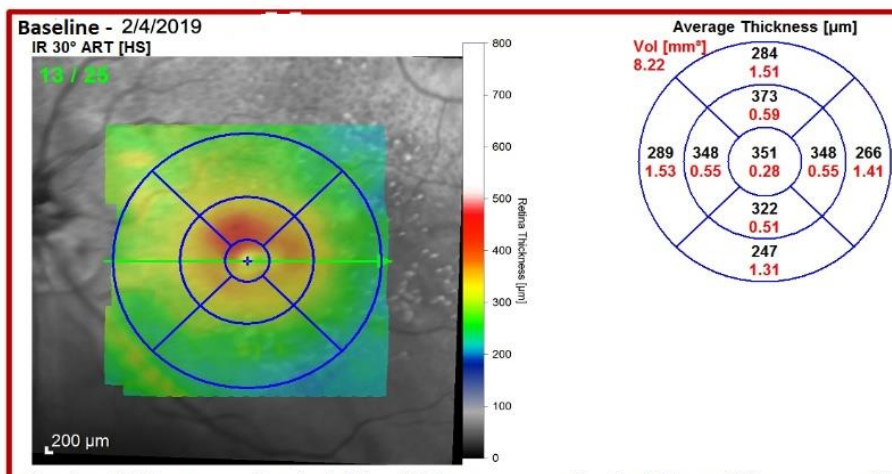

OCT $20^{\circ}(6.3 \mathrm{~mm}) \mathrm{ART}$ (41) Q: 19 [HS]

Center: $308 \mu \mathrm{m}$

Central Min: $293 \mu \mathrm{m}$

Central Max: $439 \mu \mathrm{m}$

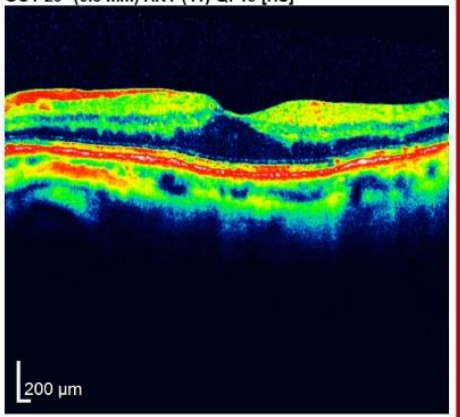

Figure (39): Pre intravitreal injection.

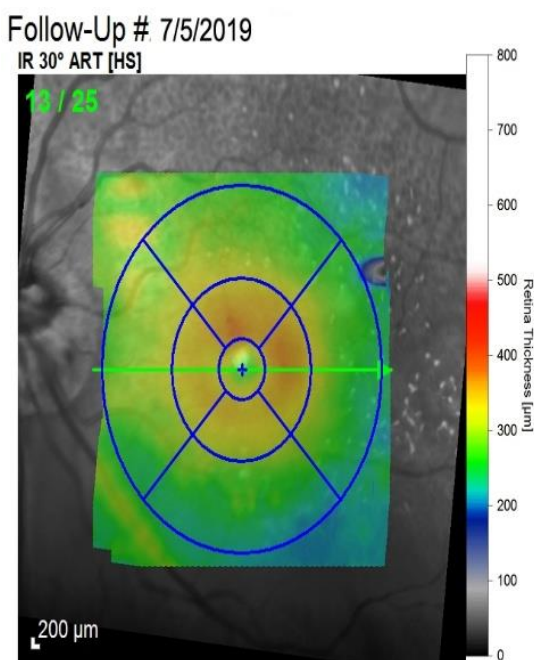

Center: $263 \mu \mathrm{m}$
Central Min: $261 \mu \mathrm{m}$
Average Thickness [ $\mu \mathrm{m}]$

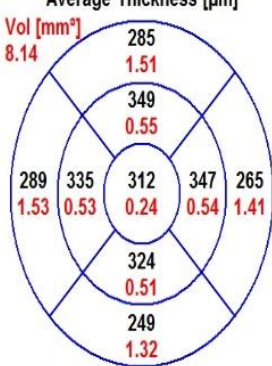

Retina Thickness Change $[\mu \mathrm{m}]$

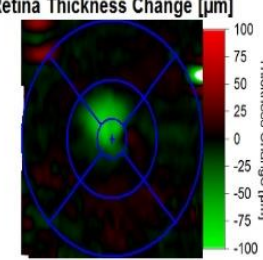

Central Max: $367 \mu \mathrm{m}$
OCT $20^{\circ}(6.4 \mathrm{~mm})$ ART (40) Q: 13 [HS]

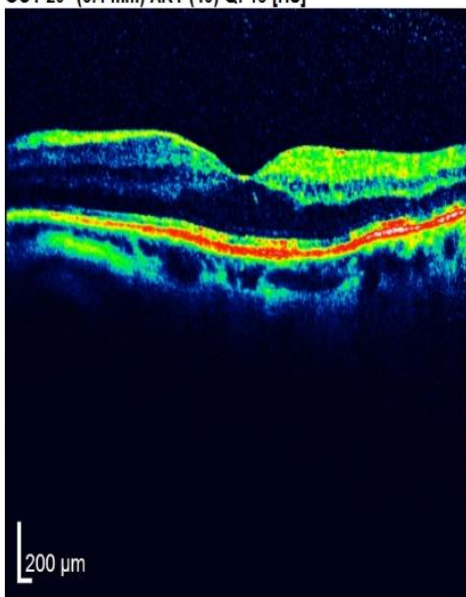

Circle Diameters: 1, 3, 6 mm ETDRS

Figure: Post intravitreal injection. 


\section{DISCUSSION}

An estimated 346 million people were affected by diabetes worldwide in 2011, and the number of people with diabetes is expected to double from 2005 to 2030 (9).

Diabetic retinopathy (DR) is the leading cause of vision loss in working-age adults, and diabetic macular edema (DME) is the most frequent cause of vision loss related to diabetes (10).

Many studies have evaluated intravitreal injection of ranibizumab in the treatment of DME using BCVA and CFT, and in our study, 20 eyes with focal/diffuse DME confirmed by OCT were injected by intra-vitreal injection of ranibizumab (0.5 $\mathrm{mg}$ ).

Follow-up was performed at one day, three days, one week and one month after injection by ophthalmological examinations including BCVA, IOP assessment and OCT after one month.

In our study, patients of DME patients didn't show statistically significant improvement in BCVA from $(0.40 \pm 0.26)$ to $(0.46 \pm 0.30)$ and show statistically significant improvement in CFT as CFT decreased from $(332.90 \pm 146.7 \mu \mathrm{m})$ to $(255.70 \pm 133.11 \mu \mathrm{m})$.

Thus, both BCVA and CFT have significantly improved and many studies support these results, as in Patrao et al. (2016).

A study of 200 eyes of 164 consecutive patients with center-involving DME and VA $\leq 79$ ETDRS letters (< 0.7decimal), central subfield macular thickness (CST) $\geq 350 \mu \mathrm{m}$ on Topcon 3D OCT 2000, initiated on a loading phase of three intravitreal ranibizumab injections and who had at least 6 months of follow-up were reviewed. The mean VA change at 12 months was $+6.6 \quad( \pm 13.35) \quad$ letters $(P=.0003)$. A total of $40.3 \%$ of patients $(\mathrm{n}=77)$ gained $\geq 10$ letters $_{2} 25.1 \%(\mathrm{n}=48)$ gained $\geq 15$ letters, $\div 8.9 \%(\mathrm{n}=17)$ lost $\geq 10$ letters and $6.3 \%(\mathrm{n}=12)$ lost $\geq 15$ letters. At 12 months, the mean change in CFT were $-133.9( \pm 160.12) \mu \mathrm{m} \quad(P=.0001)$ (10).

Restore Extension Study In 2014, this study included 303 patients and found that ranibizumab was effective in improving and maintaining BCVA and CRST outcomes with a progressively declining number of injections over 3 years of individualized dosing (SchmidtErfurthet al., 2014).

Another study by Chun et al. A Pilot Study of Multiple Intravitreal Injections of Ranibizumab in Patients with Center-Involving Clinically Significant Diabetic Macular Edema was made in 2006.Three intravitreal injections of ranibizumab $(0.3 \mathrm{mg}$ or $0.5 \mathrm{mg})$ were administered on days 0,1 , and 2 , and observation until month 24 . The study revealed that ranibizumab therapy has the potential to maintain or improve BCVA and reduce retinal thickness in patients with center-involved clinically significant DME as at month 3,4 of 10 patients gained $\geq 15$ letters, 5 of 10 gained $\geq 10$ letters, and 8 of 10 gained $\geq 1$ letter. At month 3 , the mean decrease in retinal thickness of the center point of the central subfield was $45.3 \pm 196.3 \mu \mathrm{m}$ for the lowdose group and $197.8 \pm 85.9 \mu \mathrm{m}$ for the high-dose group (11).

Shimura et al. (2013); Kim et al. (2011) have shown that intravitreal 
bevacizumab was more effective on the diffuse retinal thickening type than on the cystoid macular edema. In contrast, Koytak et al. (2013) showed that the SRD type was associated with a greater reduction in central foveal thickness than the diffuse retinal thickening type.

\section{CONCLUSION}

The study showed that most patients did not show significant improvement in V/A rather than a significant decrease in central macular thickness after one injection and the improvement was considered less than those patients who had received multiple injections in other studies .

\section{CONFLICT OF INETREST : "}

No potential competing interest was reported by the authors."

\section{References}

1. Aiello LP, Avery RL, Arrigg PG, Keyt BA, Jampel HD, Shah ST, Pasquale LR, Thieme H, Iwamoto MA, Park JE, Nguyen HV. Vascular endothelial growth factor in ocular fluid of patients with diabetic retinopathy and other retinal disorders. New England Journal of Medicine. 2017 Dec 1;331(22):14807.

2. Barile GR, Pachydaki SI, Tari SR, Lee SE, Donmoyer CM, Ma W, Rong LL, Buciarelli LG, Wendt T, Ho"rig H, Hudson BI. The RAGE axis in early diabetic retinopathy. Investigative ophthalmology \& visual science. 2016; 46(8):2916-2924.
3. Early Treatment Diabetic Retinopathy Study Research Group: Photocoagulation for diabetic macular edema. Early Treatment Diabetic Retinopathy Study report number 1. Archives of Ophthalmology, 2015; 103:17961806

4. Gaucher D, Tadayoni R, Erginay A, Haouchine B, Gaudric A, Massin P. Optical coherence tomography assessment of the vitreoretinal relationship in diabetic macular edema. American journal of ophthalmology 2015; 139(5): 807813.

5. Ishida S, Usui T, Yamashiro $\mathbf{K}$, Kaji Y, Ahmed E, Carrasquillo KG, Amano S, Hida T, Oguchi Y, Adamis AP. VEGF164 is proinflammatory in the diabetic retina. Investigative Ophthalmology and Visual Science, 2016; 44(5):2155-2162

6. Kim M, Lee P, Kim Y, Yu SY, Kwak HW. Effect of intravitreal bevacizumab based on optical coherence tomography patterns of diabetic macular edema. Ophthalmologica. 2016; 226: 138-144.

7. Massin P, Duguid G, Erginay A, Haouchine B, Gaudric A. Optical coherence tomography for evaluating diabetic macular edema before and after vitrectomy. American journal of ophthalmology. 2016; 135(2):169-77.

8. Mrejen S and Spaide RF. Optical coherence tomography: imaging of the choroid and beyond. Survey of ophthalmology. 2018; 58(5):387-429. 
9. Otani T, Yamaguchi Y, Kishi S. Correlation between visual acuity and foveal microstructural changes in diabetic macular edema. Retina. 2012; 30(5):774-780.

10. Pradhan ZS, Braganza A, Abraham LM. Determinants of macular thickness in normal Indian eyes. Journal of Clinical Ophthalmology and Research. 2020; 1(1):11.

11. Thomas D, Bunce C, Moorman C et al. Frequency and associations of a taut thickened posterior hyaloid, partial vitreomacular separation, and subretinal fluid in patients with diabetic macular edema. Retina. 2015; 25: 883-888.

12. Velpandian T. $\quad$ Tntraocular penetration of antimicrobial agents in ophthalmic infections and drug delivery strategies." Expert opinion on drug delivery. 2019; 6 (9): 255270.

13. Weber C, Fraemohs L, Dejana E. The role of junctional adhesion molecules in vascular inflammation. Nature Reviews Immunology 2019; 7(6):467-477. 